\section{A eattiruor}

\section{H O P I TAL PRACTICE, BRITISH AND FOREIGN.}

Nulla autem est alia pro certo noscendi via, nisi quamplurimas et mo: borum et dissectionum historias, tum aliorum tum proprias collectas habere, et inter se comparare.-MorgaGNI De Sed. et Caus. Morb., lib. iv. Procmium.

\section{CHARING-CROSS HOSPITAL.}

DOUBLE EMPYEMA; CONSECUTIVE REMOVAL OF RIB FROM BOTH SIDES OF THORAX ; RECOVERY ; REMARKS.

(Under the care of Mr. JOHN H. MORGAN.)

WE publish below the notes of a very interesting and unusual case of double empyema, in which the more radical operation of resection of rib was performed on both sides. There are few examples of this condition on record in which recovery followed any method of treatment, and it would be advantageous if members of the profession who have had experience of similar cases would make them known. We have brought forward a case in the Mirror, ${ }^{1}$ which was successfully treated by Mr. Okell. A child aged five years and nine months was in the Leicester Infirmary, under the care of Dr. Blunt. The symptoms had existed for seven weeks before admission, and the treatment employed was resection of rib on the right side, and on the left incision and drainage. Writing on the subject of double empyema, Mr. Godlee ${ }^{2}$ says : "Empyema on both sides of the body at the same time is almost necessarily fatal, unless one or the other be localised, except in tho-e cases in which the purulent contents are absorbed. If a general empyema have been opened, and another form on the opposite side, it is obvious that the only surgical treatment for the second collection is by aspiration." Dr. Cheadle $^{3}$ had a patient, a pregnant woman of thirty-one, under his care in St. Mary's Hospital, in whom the repeated removal of purulent fluid from both sides was folJowed by recovery. She was under care for sixty-two days. The second case is an example of the escape of a purulent collection from the thorax, and its pointing in an nnusual position. Empyemata nuy point in almost any part, but the more erratic courses are rare. Mr. Marshall considers the usual position for the pointing of an empyema to be outside and below the junction of the fifth rib with its cartilage. By others it is said that the more common situation is a point higher up in the second or third space. The following account is taken from the notes by the surgical registrar, Mr. Da Costa.

J. W. F-_, aged six, a well-nourished boy, was admitted into Charing. Cross Hospital ou March 26th, 1889, under the care of Dr. Bruce, with distressing cough and dyspnoea. Two years ago he was in St. Bartholomew's Hospital for whooping-cough accompanied with bleeding from the nose and mouth, and since then he has been delicate. His present illness began eight days before admission, when he was attacked with sore throat, and this was followed by pneumonia, for which he was attended by a doctor.

On admission the pulse was 152 ; respiration 68 . Fluid was found to be present upon both sides of the thorax, and was more extensive on the left. On this side dulness extended every where below the second intercostal space. The apex of the heart was pusher downwards and inwards, and was situated below the margin and a little to the left of the xiphoid cartilage. On the right side bubbling a were audible from the apex to the level of the sixth rib. Posteriorly dulness extended from the upper third of the vertebral border of the scapula to the twelfth rib; over this area there was marked superficial bronchial breathing and bronchophony. On the right side dulness spread downwards from the level of the angle of the scapula. Above this crepitation was heard, and in the dull area the breath sounds were very distinct. The child had a hacking cough, and lay by preference upon the left side. On the following day a trocar was introduced at the seventh left interspace a little in front of the posterior line of the

1 THE LANCET, vol. ii. 1888, p. 114. axilla, and eight ounces of nearly clear fluid were withdrawn The next day there was less dyspnoca, and the child was not so distressed. He lay on the right side and re spiration was accompanied by a short dry grunt. Tha alæe nasi were working constantly, but respiration dropped to 52 and pulse 104 . The left half of the chest moved and expanded much more than the right, but the respiration was mainly diaphragmatic. On palpation marked fremitus was observed over the upper part of the right side and to a less extent on the left. The apex beat was just below and internal to the nipple. The dulness posteriorly was much less extensive. On March 28 th the respiration was 68 and pulse 104. Subcutaneous emphysema was noticed around the site of puncture extending to some distance down over the abdomen. For the next seven days the condition did notalter greatly, but suppuration occurred at the site of the puncture, and on April 5th a hypodermic needle was introduced on the left side, but no tluid was withdrawn. On the 7 th it was introduced on the right side, and some thick purulent fluid was withdrawn, and on the 9 th $220 z$. of pus were removed by means of the aspirator. On the llth 4oz. of pus were removed by the aspirator from the left side. Pulse 120 ; respiration 62. The boy was rapidly losing flesh, and his general appearance indicated the results of impeded respiration and of embarrassed lieart's action. Mr. Morgan was asked to see him in consultation, and advised that free exit should be given to the matter on one side of the chest, by means of an incision, and, if necessary, the removal of a portion of one or more of he tribs. Accordingly on April 18th the A.C.E. mixture was administered, and was tairly well taken, in spite of the affection of both sides of the thorax. The pleura on the left side was opened, and about one inch and a half of a rib was excised. A very large quantity of healthy pus was evacuated, and a drainage-tube inserted and antiseptic dressings applied. In consequence of the patient's feeble state it was thought advisable to defer operation upon the opposite side. Great benefit ensued at once, the lung gradually expanding and occupying a larger portion of the thoracic cavity. The respiration diminished in frequency, but the condition of the right thorax prevented him from making great improvement in his general health. On April 25th twelve ounces of pus. were withdrawn by aspiration from the right chest.

On May lst, twelve days after the former operation, chlom roform was administered, which was well taken, and a similar operation was performed on the right sirle. As soon. as the pleura was opened a very large quantity of pus issued, welling up from the opening with each respiratory wave. So large a quantity came away that it was. not thought advisable to turn the child on his side lest the evacuation should be too rapid, and a drainage tube was inserted and antiseptic dressings applied. These, however, required changing the same evening, when they were found to be saturated with discharge. From this time the discharge gradually diminished, and the boy's general health greatly improved. The drawn and dusky look of the face gave way to a healthy colour, and the clubbing of the fingers, which previous to the operations had been very marked, began gradually to diminish. The respiration became less rapid and the temperature lower till the former dropped to 50 and the latter became subnormal. In seventeen days the patient gained three pounds in weight, and on May l8th the left lung filled the whole of that side of the thorax, the heart had regained almost its normal position, and all discharge from that side had ceased. The drainage-tube required to be maintained on the right side for a little longer, but by the end of the month that was removed and the sinus quickly closed, when the lung appeared to have regained its normal position.

The patient was discharged with both openings soundly healed, and was seen a month later in perfect health. He. was inspected in June, 1890, exactly a year after his discharge, and it was then found that the periosteum in the region on both sides from which portions of rib had been. removed had thrown out bone, which formed a firm covering to that part of the thorax. Respiration over the whole thorax, including the situation of the empyemata, appeared perfectly normal and the heart's apex was in its natural position.

Remarlis by Mr. MoRGAN. - There would seem to be very few instances on record in which the thorax was opened on both sides at the same time. In the case related there seemed nothing to contraindicate the operation being done 
on both sides simultaneously except the very feeble and exhausted condition of the boy, coupled with the impeded action of the heart, consequent upon its displacement by the fluid in the left pleura. The relief which is given to the pressure upon the lung by the release of the contents of a large empyema is often followed by reaction, as the component parts of the area in which pressure has been exercised expand to resume their normal position and function. Had the operations been done simultaneously the reaction migh have been too great for the exhausted condition of the patient to withstand. But for this it would have been better to relieve the thorax of the large amount of fluid which it contained as early as possible, and as soon as the reaction consequent on the operation on the left side had subsided an opening was made by which the collection in the right chest could find exit, and as satisfactory evidence that the delay was not too prolonged the lung on both sides has expanded to resume its normal position and functions. It is too of ten overlooked that an empyema is a collection of fluid limited in area and bounded by firm margins, and in which the contained fluid exercises an extreme amount of constant pressure upon the surface of lung with which it is in contact. The conditions, therefore, when an exit is given to the contents nust be in the direction of relieving pressure upon the lung, and there is no analogy between opening such a cavity as to permitting air to enter a healthy pleura, since the pressure of air which is admitted to the cavity of an empyema is limited by the margins of the abscess cavity and has less weight and power of pressure than the fluid which it replaces.

LARGE EMPYEMA, PASSING DOWN THROUGH THE DIAPHRAGM AND AMONG THE MUSCLES OF THE ABDOMEN.

H. C_- a delicate boy aged six, was admitted into Charing-cross Hospital after having been ill for three weeks. It was found that the whole of the right side of the chest was absolutely dull on percussion, the left being hyper-resonant. The intercostal spaces on the right side were bulged, and there was no movement of that side of the thorax. Below the line of the ribs and extending down nearly to the ilium was a large fluctuating swelling, having three prominent elevations, one of which was red on the surface. Fluctuation could be made between any of these prominences by pressure apon one of them, but whether they communicated with the finid in the thorax there was no means of ascertaining. An incision through the skin over the outer and posterior prominence showed that the fluid lay beneath the external and internal oblique muscles, and on incising them a large quantity of purulent fluid, estimated at about sixty ounces, was evacuated. A finger was inserted into the cavity, and was passed upwards into the right thorax, through the track of the abscess. The upper surface of the diaphragm and the inner surface of the lower ribs and intercostals could be felt, so that the fluid in the pleura must have passed between the attachment of the diaphragm to the lower ribs and separated the oblique muscles from the transversalis, and in the cellular tissue between these snuscles lay the cavity of the abscess, which formed the prominences on the surface of the abdomen. A large drainage-tube was passed through the track described into the cavity of the pleura. The temperature before operation was $101 \cdot 8^{\circ}$; respiration 50 ; pulse 155 ; the apex of the heart was displaced upwards and to the left. In the course of five days the position of the heart appeared to be normal. The temperature fell to between $99^{\circ}$ and $100^{\circ}$, but the respiration continued to be rapid; but the right chest was resonant as far down as the level of the nipple. The wound was dressed daily, but the discharge gradually diminished. On the fifteenth day after operation the temperature rose to $1028^{\circ}$, and on the following day, it being still high, Mr. Morgan examined the track of the abscess with the finger, and found that the diaphragm had been pushed upwards and backwards, thereby obstrueting the discharge. The opening having been cleared by the finger some warm water, with a very weak solution of carbolic acid, was injected, and the tube again inserted. Next day there was but little discharge, but the temperature was high, and two days later rose to $104^{\circ}$, but the respiration was only 40 . Sickness and diarrboea lasting five days may have accounted for the fever, as Dr. Green, who examined the chest, could find nothing in the condition of the lungs to explain it. As the discharge was very slight the drainage-tube was gradually shortened, and as the state of the bowels improved the temperature gradually sank, until at the end of sixteen days from the second examination it was little above $99^{\circ}$. Meanwhile the lung had expanded, until on April lst respiration could be heard over the normal areas, and on the following day the tube was left out. The wound had completely healed in another twelve days, and the boy had gained two pounds and a half in weight. Before his discharge it was reported that the breath sounds, although weaker than on the left side, could be distinctly heard almost as low as in the opposite side. The chest wall has not very good expansion, but movements are perfectly visible. Resonance is impaired, especially at the base, but nowhere quite dull. The boy was sent to the country, and has since attended to show himself, and appears to be in perfect health, and has gained considerably in flesh.

\section{WOLVERHAMPTON GENERAL HOSPITAL.}

SOME CASES OF TRACHEOTOMY FOR SCALD OF THE LARYNX; REMARKS.

(Under the care of Mr. J. HARLEY Gough, late house surgeon, now resident medical officer to the Royal Albert Hospital, Devonport.)

CASES of scald of the mouth, on account of their urgency for treatment, come more especially under the care of the residents in our hospitals, and when the larynx has been directly involved, the treatment must often be prompt and decided, if the life of the child is to be saved. We publish a series of cases in which urgent dyspnoea was present, and in which tracheotomy was performed by Mr. Gough with varying success. We do not know of any statistics or published results of the use of intubation in scald of the larynx. A comparison of tracheotomy with intubation, when employed for urgent dyspnca due to membranous laryngitis, gives much the same average percentage of recoveries after each.

CASE 1._James C___ aged three, was admitted into the Wolverhampton General Hospital early in the morning of Nov. 17th, 1886, having sucked the spout of a kettle containing boiling water about six o'clock the evening before. His parents said that soon after the accident his breathing began to get croupy, and during the night became very much worse, and on that account they brought him to the hospital. On admission, the child was much exhausted; respiration was performed with difficulty, the chest walls being drawn in during each attempt at inspiration; the tongue was coated with a thick white fur, and the uvula and fances were swollen. The patient was at once put to bed, and the cot was surrounded by a tracheotomy tent. Hot moist sponges were applied to the throat, and steam from a bronchitis kettle was conveyed into the tent. The child's condition, instead of improving, became worse, and tracheotomy was performed about an hour after coming into the hospital. The relief from the operation was almost instantaneous, the breathing became quiet and natural, and the pulse soon regained its normal volume and number of beats. Enemata of brandy (half a drachm), beef-tea (four drachms), and milk (four drachms) were given every four hours for the first thirty-six hours, after which the child took plenty of liquid nourishment by the mouth. The tracheotomy tube was removed on the fourth day, and the patient left the hospital cured on Dec. 12th, 1886.

CASE 2.-Charlotte U-, aged three, was admitted into the Wolverhampton Hospital on Nov. 24th, 1886, having drunk some boiling water about four hours before. On admission there was much inspiratory dyspnœa and exhaustion, which rapidly became worse, in spite of treatment-viz, tracbeotomy tent, inhalation of steam, hot sponges to the throat, - and tracheotomy was performed about two hours later. When the child was put back to bed after the operation she at once fell into a natural and sound sleep. Nutrient enemata were given as in the preceding case. On the fifth day the tracheotomy tube was removed, but had to be reintroduced thirty-six hours later on account of dyspncea after a fit of coughing. It was removed again three days later, and had to be replaced in ten hours' time, but a soft indiarubber tube was substituted for the silver one, which was finally removed on the eighteenth day, and the patient left the hospital cured on Dec. 21 st, 1886.

CASE 3.-Joseph $\mathrm{C}-$, aged three, was admitted into 